\title{
FRAGMENTOS DE DISCURSO HETEROGÊNEO DE IDOSOS NUM ESPAÇO HOMOGÊNEO DE CARÊNCIA E PARTILHA ${ }^{1}$
}

\author{
Sérgio da Costa Brito* \\ Sergio Antonio Carlos*
}

\section{Resumo}

Este trabalho busca descrever-interpretar o discurso corrente entre os moradores de uma Instituição de Longa Permanência localizada no Estado do Rio Grande do Sul e organizada para um público composto por artistas idosos sem recursos de moradia própria. Busca-se através desta análise estabelecer parâmetros para contribuir com a reflexão sobre modelos institucionais voltados para esta faixa etária orientados para grupos sociais estritamente delimitados por critérios como profissão, origens étnico-culturais, espiritualidade entre outros.

Palavras-chave: Envelhecimento. Artistas Idosos. Instituição.

\section{Introdução}

Sabe-se que, no Brasil, a realidade sócio-econômica muitas vezes relega a população idosa a uma situação aquém do que se poderia considerar como dignamente assistida, deixando não satisfeitas necessidades básicas de sobrevivência. A sociedade e o Estado seguem buscando manter a inserção social do cidadão idoso através das políticas sociais visando sua subsistência (BULLA; MEDIONDO, 2004). Neste contexto, torna-se relevante estudar, descrever, interpretar as realidades no interior mais íntimo dos espaços de vida e moradia coletiva destinados a esta faixa etária, num exercício de análise das suas propostas de estruturação, buscando saber quanto se consegue alcançar dos resultados idealizados na focalização de objetivos iniciais.

\footnotetext{
1 Artigo baseado na dissertação "O Retorno aos Bastidores” apresentada ao Programa de Pós-Graduação em Psicologia Social e Institucional do Instituto de Psicologia da Universidade Federal do Rio Grande do Sul, pelo primeiro autor sob a orientação do segundo.

* Psicólogo, Mestre em Psicologia Social e Institucional pela Universidade Federal do Rio Grande do Sul (UFRGS). E-mail: sbrito@terra.com.br

*** Doutor em Serviço Social, professor do Programa de Pós-Graduação (PPG) em Psicologia Social e Institucional da UFRGS. E-mail: sacarlos@ufrgs.br
} 
O objetivo deste artigo é analisar o discurso produzido no espaço de vida por moradores de uma Instituição de Longa Permanência para artistas idosos sediada no Estado do Rio Grande do Sul buscando, pela descrição/interpretação dos efeitos de sentido aí surgidos, avaliar as circunstâncias de envelhecimento e afastamento do trabalho.

Considerando as características do tipo de residência, em muitos aspectos, diversa da maioria das instituições de longa permanência para idosos que se conhece no Estado, em que medida a proposta institucional favorece ou dificulta uma qualidade de vida satisfatória? Que relações se estabelecem entre a vivência dos diferentes papéis profissionais ocupados por cada um no passado e a realidade do convívio atual na instituição, estando todos institucionalmente em situação de igualdade?

Muito antes de se avaliar criticamente esta proposta de instituição como local de moradia para artistas idosos, deve-se lembrar do que realmente é: a única alternativa para os atuais moradores, independentemente de ali estarem pelo fato de corresponderem a um perfil determinado. Admite-se que a sociedade tem responsabilidade com cada um destes idosos, em função do que significaram na vida social como cidadãos e do que podem representar como memória viva de um passado que mantém a identidade cultural do Estado. As questões sobre a qualidade de vida dentro da instituição, devida à rede de relações institucionais resultantes de um passado em comum, estão submetidas ao valor que a instituição em si representa para pessoas que, sem essa alternativa, não teriam onde se abrigar.

\section{As Instituições de Longa Permanência}

A velhice, pensada na perspectiva do coletivo, exige um planejamento de assistência que abranja as diversas camadas da sociedade. De acordo com Quadros (1998), as desigualdades na distribuição de renda em nível mundial, assim como as grandes diferenças sociais entre as populações dos países em desenvolvimento como o Brasil, com as conseqüências que isso lhes acarreta, decretam que o caminho do asilo para o cidadão idoso torna-se inevitável.

O Brasil compõe-se de uma população heterogênea em diversos aspectos étnicos e sociais. Marcado pela diversidade cultural e pelas 
desigualdades econômicas, reflete uma grande variedade de instituições asilares que revelam suas diferenças quanto a padrões de atendimento, qualidade da estrutura, organização financeira, população atendida e até de denominações adotadas (BORN; BOECHAT, 2002). Devido a tal diversidade de tipos de estabelecimento e à modificação nos padrões de atendimento em grande parte deles, novos conceitos vão sendo instituídos em substituição a "asilo", que carrega uma conotação puramente assistencial.

Existe uma legislação que regula os direitos dos cidadãos brasileiros com mais de sessenta anos, bem como as obrigações e normas destas instituições. Esta regulação está descrita no Estatuto do Idoso (BRASIL, 2003)2 . O título IV do Estatuto trata da Política de Atendimento ao Idoso; no capítulo II deste título estão descritas as formas e obrigações previstas para as entidades de atendimento ao idoso, ou instituições de longa permanência (ILP).

Entre as obrigações das entidades, está a manutenção das próprias unidades, devendo estar essas entidades devidamente inscritas no órgão competente da Vigilância Sanitária e no Conselho Municipal do Idoso. Além disso, essas instituições devem oferecer instalações físicas em condições adequadas de moradia para o idoso, apresentar objetivos estatutários, estar regularmente constituídas e demonstrar a idoneidade de seus dirigentes. Entre os princípios que deverão reger seus programas de funcionamento, estão: a preservação de vínculos familiares, o atendimento personalizado, a manutenção do idoso numa mesma instituição, a participação do idoso em atividades comunitárias, a observância dos direitos e garantias do idoso e a preservação de sua identidade. Deverá haver um contrato de prestação de serviço com o idoso em que haja a especificação do tipo de atendimento e as obrigações da entidade para com ele. Entre outros compromissos, de acordo com os artigos 48 a 50 do estatuto do Idoso, a instituição deverá proporcionar atendimento em saúde, conforme as necessidades do idoso; promover atividades educacionais, esportivas, culturais e de lazer; proceder o estudo social e pessoal de cada caso e manter no quadro de pessoal profissionais com formação específica para bem atender seus residentes (BRASIL, $2003)^{3}$.

${ }^{2}$ Documento eletrônico

${ }^{3}$ Documento eletrônico 
Os aspectos que envolvem a institucionalização como acontecimento na vida do indivíduo são vários, com ênfase sobre a questão psicológica (BORN; BOECHAT, 2002). O indivíduo que vem a ser residente em uma instituição de longa permanência acumula incertezas referentes à sua real percepção da extensão dessa alteração no plano de sua vida, o que gera dúvidas sobre o destino de sua privacidade social, do seu sentido de propriedade, da continuidade de sua participação no quotidiano daqueles que ele deixa para trás, somados à insegurança quanto ao seu futuro e ao enfrentamento do desconhecido.

Segundo Born e Boechat (2002), em uma situação ideal em que se pudesse fazer oposição a essas contingências, a instituição deveria se munir de um olhar atento e de uma visão ampla, empática com a dimensão e o significado desse momento, de modo a prover alívio do medo e da ansiedade. Esses autores enfatizam a necessidade de uma cuidadosa fase de transição até a entrada na instituição, na qual a seleção e a preparação do idoso seriam acompanhadas de apoio profissional, contando com a participação, decisão e opiniões do futuro residente.

Os recursos humanos desses estabelecimentos deveriam contar com uma equipe permanente compondo-se de médico, assistente social e nutricionista, além dos serviços de limpeza, segurança, lavanderia, copa-e-cozinha e cuidadores, mais a equipe de enfermagem, formada por enfermeiro, técnico em enfermagem e auxiliar de enfermagem. (SOCIEDADE..., 2004). Lembrando-se do referido sobre as desigualdades da sociedade brasileira, que faz do envelhecer uma experiência diversa conforme as diferentes camadas da população, pode-se questionar esse quadro prescrito, tendo em vista a grande quantidade de instituições funcionando com verbas mínimas, calculando-se, desse modo, o grau de carência em que elas se encontram em relação a esses critérios.

\section{O Contexto, os Objetos de Análise, o Percurso Traçado}

O contexto, aqui, refere-se à instituição de longa permanência onde vivem os artistas idosos afastados de sua atividade profissional formando com eles o objeto mesmo de pesquisa. Ela está colocada como pano de fundo dando contexto às contingências de vida dos participantes. A análise do material colhido seguiu um padrão de processo que se baseou nas escolhas teórico-técnicas descritas nos itens subseqüentes. 


\subsection{Sobre a Instituição Pesquisada}

A instituição foi fundada com a finalidade de abrigar artistas afastados do seu trabalho sem condições de prover o próprio sustento, contando com auxílio externo. Trata-se de estabelecimento de direito privado; sua diretoria está devidamente registrada e é considerada de utilidade pública em nível municipal e estadual.

A manutenção da casa provém de diferentes fontes, sem uma ordenação sistematicamente garantida. Há um esforço para manter uma estrutura institucional mínima, mas ainda não se possui um quadro social que dê à casa uma sustentação mais segura.

A cada mês, a diretoria tem de sair em busca de recursos para o período, pois não há doações permanentes. Em seu primeiro ano de gestão, obteve uma verba para doze meses junto a um político sensível à situação dos trabalhadores do rádio, mais alguma soma vinda de uma fundação. Há também pessoas físicas e organizações que realizam doações de alimentos; estas fontes, em geral, levam os produtos doados até os moradores.

Algumas vezes, alguns dos moradores fazem certos trabalhos ainda possíveis em suas antigas áreas de atuação e auxiliam com uma parte do que arrecadam. Já houve um músico gravando um CD com antigos colegas, outro que se apresentou acompanhando ao violão uma cantora num programa de televisão, um roteirista de rádio-teatro escreveu uma rádio-novela para ser transmitida por uma emissora do interior. Entretanto, são pequenos trabalhos que não chegam a prover o sustento completo de suas necessidades básicas.

Para ingressar na instituição, cada novo morador deve passar por um processo de avaliação, que se dá basicamente através de entrevista com a direção da casa. A condição básica para aceitação do candidato é que ele tenha sido artista profissional, estando efetivamente na falta de recursos financeiros para residir em outro local por conta própria. É exigido que o futuro residente comprove suas atividades de trabalho na área artística, não necessariamente com carteira de trabalho assinada, mas de alguma outra forma material e objetiva. São esperados do candidato a morador a boa convivência e aceitação das combinações, inclusive quanto às atribuições na distribuição dos serviços de manutenção do local. 
Todos os moradores têm plena liberdade de ir e vir no horário que desejarem, as refeições são preparadas individualmente segundo horário e recursos próprios na cozinha comum ou mesmo nos quartos. Não há quadro de funcionários no local, nem mesmo para limpeza, somente os residentes. Os moradores da instituição vivem sozinhos no local, compondo uma pequena comunidade formada por indivíduos que, em vários casos, conhecem-se de outras épocas de suas vidas. Alguns deles foram artistas de cena, como atores, músicos; outros foram roteiristas ou diretores, e há também profissionais que exerceram uma função de auxílio técnico aos que representavam, como técnico de som, costureira, cabeleireira cênica, camareira.

O diretor freqüenta o local com regularidade e, em geral, ele é informado da entrada de pessoas estranhas à casa (exceto parentes e amigos próximos) tais como pessoal de imprensa, estudiosos ou estudantes.

\subsection{Observações sobre as Visitas realizadas ao Local}

Os contatos entre pesquisador e participantes em sua instituição de residência ocorreram no ano de 2004, referindo-se a este tempo os dados sobre a estrutura analisada. Primeiramente foram feitos dois contatos com o diretor, que cedeu informações sobre a instituição e aceitou que se fizessem visitas e um trabalho de observação no local.

O processo de aproximação com esta instituição iniciou-se por visitas regulares nas quais buscou-se conhecer o perfil de relações operante dentro da mesma, o estilo de comunicação verbal e pré-verbal e os níveis de proximidade/distanciamento entre seus moradores.

$\mathrm{Na}$ manhã do dia em que se realizou a primeira destas visitas, ocorrera um fato que envolvera intensamente os moradores, uma dissensão causada pela conduta de um deles que desagradara a outros três colegas. A expressiva experiência de stress por que todos os três claramente aparentavam ter passado demonstrava o grau de ansiedade contida que trasbordara de modo instantâneo, segundo os relatos, inclusive redundando no mal-estar físico de um dos residentes que sofre de uma cardiopatia. Curiosamente, a par disto observou-se o quanto o desagradável da situação conflitante não os impedia de emprestar um certo grau de valor ao fato de que o seu local de moradia era um espaço de 
explosões temperamentais recorrentes, como que deixando o sentido latente de sempre haver um passatempo para se ocuparem. Foram relatadas situações de discórdia com momentos de surpreendente nível de agressividade.

A desconfiança entre os moradores chama a atenção como um fato facilmente detectável ao se entrar em assuntos sobre a direção da casa, tanto a atual quanto as anteriores. Alguns se posicionam mais abertamente em suas críticas à forma de se conduzir os interesses gerais da instituição, com acusações de protecionismo, falta de realismo na administração ou passividade na manutenção dos poucos recursos de que eles dispõem. Outros, muito reticentes, não se arriscam a verbalizar suas críticas, transparecendo a fantasia de que seus relatos e opiniões cheguem aos ouvidos da direção, revertendo em represálias ou em alguma forma de prejuízo. Mas o descontentamento é quase geral, ainda que mantido sob discrição, pois cada morador tem consciência de seu grau de dependência da instituição, que é o de não ter um espaço de moradia em caso de ter que deixar o local, o que em realidade pode acontecer.

Percebe-se uma grande diferença de enfoque por cada um deles a respeito da instituição. Ouve-se dizer que se trata de um asilo, uma casa para onde se vai porque tudo para eles terminou, ouve-se qualificá-la como uma república, pois cada um tem sua liberdade, seu espaço, seus horários, suas despesas pessoais por sua própria conta e risco, afora os quartos, a luz e a água, providos gratuitamente. E ouve-se também referência afetiva de expressiva gratidão por possuírem um espaço de moradia em situação de dificuldade econômica, embora isto seja manifesto com discrição e afastamento físico dos demais moradores e do próprio prédio, remarcando a postura de cautela e resguardo que se observa entre todos em linha geral.

O dia-a-dia dá-se de forma independente. O uso da cozinha, comum a todos, é individual, havendo a regra de mantê-la limpa e desimpedida para o próximo morador a ocupá-la. Há dias em que o tom reinante é mais individualista, outros em que alguns deles se unem para preparar suas refeições conjuntamente, ocorrendo agrupamentos por ordem de afinidade com eventuais momentos de ajuda mútua. Ao ponto destas visitas havia somente um banheiro em ordem de funcionamento, dividido entre homens e mulheres e localizado no segundo pavimento. A manutenção da higiene é uma exigência de regra, sendo reivindicada 
por alguns em relação a outros de modo contundente.

Uma sala de visitas central no andar térreo é ponto de encontro entre os moradores, que ali se reúnem para conversar, tocar violão e cantar ou receber visitantes. Eventualmente, a direção promove momentos de descontração entre eles, como alguma pequena reunião noturna com vistas a uma maior integração entre antigos colegas. Nem todos participam destas reuniões, ou só raramente, por não demonstrarem interesse num convívio próximo com os demais.

\subsection{Escolha dos Moradores/Participantes}

Depois das visitas iniciais, decidiu-se por abordar três dos moradores, que correspondiam mais exatamente ao perfil de candidato a residente determinado pela proposta institucional, ou seja, três idosos afastados do trabalho exercido no campo das artes cênicas. Tal escolha se deu pela consideração de que estes idosos poderiam oferecer dados sobre a qualidade de vida dentro da proposta da instituição em situação de maior coerência com a verdadeira destinação da mesma. Outros moradores também correspondiam a este perfil, mas por questões de horário, estado de saúde ou interesse em colaborar, definiu-se os selecionados a partir da disponibilidade apresentada.

Realizaram-se separadamente com os participantes entrevistas semi-dirigidas individuais com documento redigido e assinado de consentimento informado para uso por parte do entrevistador do material colhido. Estas entrevistas, de aproximadamente quarenta minutos cada uma, foram gravadas em áudio e posteriormente transcritas mantendose rigorosamente o modo de expressão verbal dos entrevistados. Buscou-se nestes contatos conhecer suas histórias de trabalho e de vida, e, principalmente, as condições de vida presente, os relacionamentos, as impressões da vida na instituição, as relações passado/presente, as expectativas de futuro, identificando sentimentos e estratégias de enfrentamento da realidade atual.

Num segundo momento, selecionou-se fragmentos dos textos das transcrições das mesmas buscando ilustrações verbais a respeito do viver na instituição, as quais se reproduz neste trabalho.

Por fim, passou-se ao processo de Análise de Discurso do material verbal coletado, contextualizado sobre registros das situações am- 
bientais e não-verbais de entrevista.

O contexto em que se encontram os participantes desta pesquisa é de final de uma vida de trabalho na qual sempre estiveram mergulhados numa atividade com significado vital, além de prático, essencialmente existencial, dado a atividade artística relacionar-se diretamente com a percepção do mundo e de si mesmo pelo indivíduo e com a expressão permanente do (e no) seu meio de imersão na vida (OSTROWER, 1977).

Nenhum dos três entrevistados tem estudo formal além do Ensino Médio, e a formação artística de caráter formalizado foi quase nenhuma; todos aprenderam o ofício diretamente na prática. Designados por nomes fictícios, apresentam as características pessoais descritas nos itens a seguir.

\subsubsection{Eva}

Eva tem setenta e seis anos, é atriz e solteira. Vive na instituição há vinte e cinco anos. Nasceu no interior do Estado do Rio Grande do Sul e desde criança determinou que seria uma artista. Sentia-se, e ainda sente-se, diferente dos irmãos, uma pessoa à frente do seu tempo. Considerava as mulheres de sua juventude muito atrasadas, sem curiosidade, sem o sentido da busca pelo conhecimento. Eva chegou a casar-se, mas divorciou-se em seguida. De sua família atual, comenta apenas os sobrinhos que moram longe e que lhe representam grande fonte de afeto.

Iniciou no rádio em 1951 e trabalhou dos 21 aos 68 anos. Conta que foi famosa, uma figura pública presente no dia-a-dia da cidade. Atualmente, faz pequenas apresentações, muitas vezes sem cachê ou por uma quantia pequena. Segundo ela, a modalidade teatral em que trabalhava se extinguiu da realidade cultural do país.

\subsubsection{Hélio}

Hélio, sessenta e dois anos, diretor e roteirista, solteiro e sem familiares, reside no local pelo terceiro período em sua vida.

Guarda a recordação viva das difíceis perdas de seus familiares próximos, razão pela qual foi discreto a respeito de sua história de vida 
familiar.

Nos anos setenta, iniciou-se profissionalmente como roteirista de rádio-teatro no Estado do Rio Grande do Sul, quando escrevia para os grandes atores e atrizes da época. Também deu aulas de teatro, tendo alcançado amplo reconhecimento em seu meio de atuação. Nos últimos anos, não tem tido muitas oportunidades de trabalho em sua área, obrigando-se a outros tipos de serviço informais para garantir sua subsistência.

A imagem que verbaliza da instituição é realista e positiva, considerando-a vital por ser uma alternativa entre raras outras para ele e seus colegas terem onde morar.

\subsubsection{Waldemar}

Com 69 anos, Waldemar é músico aposentado formalmente, mas esporadicamente realiza atividades remuneradas segundo as oportunidades que aparecem. Foi casado, teve sete filhos e vários netos.

Iniciou profissionalmente em 1951 em Porto Alegre e trabalhou como músico a vida inteira: não exerceu outros tipos de atividade durante sua vida de trabalho. Depois de trinta anos no rádio, passou para a televisão por sistema de cachê, também acompanhando cantores em espetáculos noturnos. Ele está residindo na instituição há dois meses, mas pensa em mudar-se em breve. Basicamente, sua imagem do local onde está vivendo é indiferente, mas com uma postura crítica; acha que é excessivamente deficitária do ponto de vista financeiro e acredita que algumas determinações nela mantidas deveriam ser revistas.

\subsection{O Processo Descritivo}

A Análise de Discurso busca trazer à luz efeitos de sentido latentes no material de um dado discurso, considerando o seu contexto de produção como sendo-lhe simultaneamente constituinte e constitutivo. A possibilidade de sentidos de um discurso será tão profusa quanto forem numerosos os leitores e ouvintes que entram em contato com os enunciados que o compõem, pois estes enunciados serão decodificados sempre a partir de um contexto, sendo este entendimento necessariamente efetuado a partir de uma ótica determinada sóciohistoricamente. 
Retomando antiga questão da Análise de Discurso, Possenti (2001) questiona de onde vêm os sentidos que se afirma serem atribuídos pelos leitores a um texto lido (como no caso do material de uma entrevista lido pelo pesquisador). $\mathrm{O}$ autor ressalta que o universo discursivo onde se inscreve uma situação de enunciação é anterior aos enunciados (os ditos) que a compõe. Tal universo contém tanto o enunciador (no caso da entrevista, o entrevistado) quanto o co-enunciador (no mesmo caso, o entrevistador). Ele perpassa os enunciados destes últimos, dando contexto e condição de surgimento ao que é dito e mostrado, influindo sobre a leitura dos sentidos conforme o lugar de cada participante da cena enunciativa.

Em Análise de Discurso, Maingueneau (2001) afirma que é o corpus, ou conjunto dos fragmentos de discurso delimitados para fins de descrição/interpretação, quem define o objeto de pesquisa, o qual não existe anteriormente a esta delimitação. Os participantes deste estudo reunidos compuseram, a partir da heterogeneidade de suas falas - considerando-se o caráter singularizante do processo de envelhecimento - um perfil característico do discurso produzido pelos moradores da instituição, o qual se buscou descrever.

\section{Viver na Instituição}

A vida nesta casa transcorre de forma algo afastada, ou, pelo menos, esquecida do que se passa fora de seus muros. Em alguns momentos, é clara a marca da individualidade, presente na expressão de cada um, como se pode ver pelo seguinte fragmento do depoimento de Hélio:

Hélio: "Por aqui, apesar de cada um levar a sua vida praticamente..., entendeu, a gente se fala muito, entendeu, a gente se ajuda muito com palavras. É um diálogo, um diálogo aberto.”

Hélio repete, nesse fragmento, certa disposição para interpretar situações e relações de um modo subjetivo, a partir de uma perspectiva bastante otimista. Assim, o emprego do "[ . . . ] apesar [ . . . ]", sugere uma heterogeneidade discursiva implícita no interior da própria frase que ele formula. 
A expressão "[ . . . ] a sua vida [ . . . ]" denota uma idéia de independência entre os moradores, e o advérbio "[ . . . ] praticamente [ . . ] ]", ao fazer-se seguir por uma pausa, indica a idéia de que o cada um levar a sua vida independente dentro da instituição é uma realidade presumível. O "[ . . . ] entendeu [ . . . ]", repetindo-se muitas vezes ao longo de suas falas, vem sempre em substituição a uma palavra que, por sua obviedade, não merece ser mencionada, sob pena de incorrer em redundância, dado a idéia ser significativa dentro do contexto do que diz. Essa palavra prepara o interlocutor para a idéia seguinte, de cunho contrário, quer dizer, "[ . . . ] a gente se fala muito [ . . ]", "[ . . ] é um diálogo aberto." Na verdade, ambos traços característicos identificados por ele na instituição não são necessariamente excludentes. Hélio aponta para a possibilidade que reconhece de haver respeito à privacidade, mas também espaço para a franqueza, para a interação desinteressada entre eles. O "[ . . . ] praticamente [ . . . ]" revela que, de fato, os moradores da instituição têm uma existência bastante separada uns dos outros, o que vem a ser confirmado pela fala de Eva:

Eva: "Eu me levanto sozinha e saio caindo aos pedaços, mas eu vou procurar um recurso, né? Porque aqui ninguém pode fazer nada por ninguém."

Antes, Hélio afirma que os residentes se ajudam muito com palavras, um tipo de convívio proveitoso que Eva não prioriza em sua descrição, ao falar na ausência de recursos financeiros. Para ela, a carência material é a característica preponderante da casa: não deixa espaço relevante para o exercício da solidariedade, para os vínculos satisfatórios de mútua confiança.

A realidade dos recursos limitados toma para Eva uma dimensão de destino, de força maior. "[ . . . ] aqui ninguém pode fazer nada por ninguém", ou seja, mesmo que haja relações humanas, todos os moradores são limitados por uma realidade material que cerceia suas possibilidades de partilharem essa solidariedade que Hélio sublinha, mostrando-se ele, em relação a Eva, mais disposto a enxergar uma imagem continente entre as diferentes faces que a casa compõe. Ninguém poder fazer nada por ninguém, como diz Eva, para ele significa que, como o entrevistador deve compreender, cada um leva " [ . . . ] sua vida 
[ . . ]." " [ . . ] praticamente... [ . . ] ]" - isolado? Sozinho? Sem dividir o que tem? Especificamente sobre isso, ele nada chega a verbalizar, posto que, para ele, é tão claro que não precisa ser dito: mas o que importa a ele dizer é que há uma qualidade humana simultânea, as pessoas dividem palavras, na falta de recursos materiais; compartilham afeto, preocupações mútuas.

Waldemar se posiciona de um modo mais próximo ao de Eva, ressaltando muito mais as questões de ordem financeira do que as que dizem respeito à dimensão do convívio humano. Durante sua entrevista, ele foi muito discreto no tocante às suas críticas, temendo, talvez, que o registro de suas opiniões pudesse comprometê-lo de algum modo posteriormente, como ele próprio manifestou. Fora do momento da gravação, ao final da visita, comentou que algumas normas novas estavam sendo propostas pela direção quanto à manutenção da casa. Isto causou revolta e acendeu velhas discussões sobre quem teria, realmente, direito a residir ali, e quem não teria, quem era a rigor um artista aposentado e quem, em outros tempos, desempenhara funções junto ao meio artístico que não se configuravam como atividades artísticas propriamente ditas. Isto gerou uma postura discreta e retraída em Waldemar, deixando-se entrever, entretanto, uma mensagem não de todo partilhada:

Waldemar: "Aqui tá ótimo, tá ótimo, tô gostando! Se Deus quiser, vai melhorar mais ainda, se Deus quiser...'

Diante da diversidade de opiniões e gostos, numa realidade na qual todos são pessoas habituadas a externar opiniões individuais com intensidade e muita ênfase, Eva revela uma questão já mencionada ao longo dos contatos iniciais, inclusive por outros moradores, deles não se sentirem amparados pela instituição enquanto instância superior a uniformizar a rede de relações organizando esquemas de vida quotidianos, mediando as diferenças e assistindo-os em situações de conflito:

Eva: "[ . . . ] eu sempre digo que aqui deveria ter uma pessoa com quarenta, cinqüenta anos, bem lúcida, bem equilibrada, que dirigisse a casa."

Eva não ignora ser essa a idade do diretor da casa. O que ela quer 
dizer é que, talvez, os moradores precisassem que ele residisse lá, que estivesse com eles no dia-a-dia. Ela descreveu situações de confronto durante as quais se manifestava a intensidade emocional de alguns moradores. Para ela, o artista é " $[$. . . ] uma pessoa diferente [ . . . ]", talvez mais temperamental do que as pessoas comuns. Ela sente falta de alguém com uma capacidade maior de racionalização sobre os pontos do enredo quotidiano, sente falta de uma harmonia e clareza de julgamento que não encontra na rede formada por ela e seus colegas. Não deixa de mencionar nesse momento o que diz também em outro ponto de seu depoimento, sobre o quanto não se apega a nenhuma relação ali dentro, sobre o quanto se sente pouco ligada a essa instituição, apesar de viver nela há vinte e cinco anos:

Eva: "Ela é dos artistas, quer dizer, é de tudo e não é de ninguém. Pra mim não é minha, né, pra mim ela é uma casa onde eu passei uns tempos, né?"

O grupo não é sentido como um coletivo organizado que se aproprie de seu espaço de vida no sentido de um laço de pertencimento vincular. Para além de considerar que os moradores, em sua quase totalidade idosos, não sejam capazes de se gerir plenamente em diversos sentidos, Eva dá a entender que tampouco estão aptos a isso enquanto grupo - argumento que se reforça no teor um pouco trágico de suas palavras ao expressar sua situação de ter de buscar auxílio por si mesma em um momento de adversidade "[ . . . ] aqui, ninguém pode fazer nada por ninguém."

Sendo assim, sua estada ali significa escassez de recursos e fim de vida, uma inegável decadência em relação ao que ela e seus colegas de profissão e abrigo viveram na juventude e maturidade como pessoas solicitadas e bem-sucedidas, ou ao menos com boas oportunidades de trabalho. Mas também fica clara a vinculação da imagem da casa com a imagem da pessoa: não ser de ninguém, não ter ninguém que os assista, não ter a gratificação de pertencer a alguém, haja visto, no caso específico de Eva, não se sentir nem mesmo pertencente à casa: “[ . . . ] eu tenho outra personalidade, outra maneira." A realidade das relações institucionais os remete para muito longe da possibilidade de se sentirem integrados uns aos outros, como indivíduos que, afinal, partilham 
uma memória comum que poderia ser compreendida em perspectiva de integração.

Waldemar dá o tom realístico e objetivo a essa mensagem subjacente da fala de Eva:

Waldemar: "Agora eu tô aqui [ . . . ] dois meses que eu tô. Tô sozinho mesmo..."

A instituição, portanto, é o local para onde os artistas vão quando estão sozinhos. Waldemar morava com o seu filho mais velho, também músico. Sob pretexto de que no novo local ficaria mais perto "de tudo", do centro da cidade, dos locais onde poderia trabalhar, onde poderia fazer contatos profissionais, veio viver ali. Depreende-se motivos encobertos em seu depoimento, não ficando claro se seriam de ordem financeira ou familiar. Mas quando ironiza a respeito de seus rendimentos com a aposentadoria, seu tom amargo faz com que se compreenda a sua dor pelo pouco poder de decisão a respeito de como será sua vida, que está ligada a uma situação financeira bastante desfavorável.

Para Beauvoir (1990), o velho nem sempre escolhe como será sua velhice, pois esta, como fenômeno não apenas biológico, mas também social, é determinada historicamente pela realidade das diferenças de classe. Waldemar demonstra a frustração de viver essa contingência.

O fato é que ele diz estar "[ . . . ] sozinho, mesmo [ . . . ]", quer dizer, nada o prende em outro lugar, nem o vínculo com a esposa, pois é viúvo, nem com os filhos. Tanto faz estar ali, se está sozinho, não há um lugar melhor para ele no momento, pois está só; não é bom ou ruim estar ali; a instituição não lhe significa muito. É onde ele está em convívio direto com pessoas que partilharam um mundo que hoje não existe mais e do qual apenas os colegas dos quartos ao lado e mais alguns outros indivíduos idosos de nossa cidade e de nosso Estado são ainda testemunhas, e mesmo assim o lugar não é melhor nem pior do que estar solitário na velhice, sem trabalho e sem renda suficiente para se sustentar. Afinal, é justamente essa a finalidade: ampará-los; mas, ao fazer isso, também se os representa na fachada e na estrutura de sua situação - uma construção descuidada, com aspecto de abandono e interior compartimentado, em que cada quarto é um mundo isolado, o ponto final de 
uma trajetória ou uma transição indefinida, como diz Eva: "[ . . . ] uma casa onde eu passei uns tempos", ou ainda um ponto instável, de continuidade imprevisível, como reflete Waldemar: "Nada é eterno."

Significar a instituição, para esses moradores, é significar também um momento de vida: o ato de fazê-lo vai carregado com o estilo e as iniciativas de cada um no modo como gere a sua vida de emoções, no modo como extrai o que é possível, conforme a sua capacidade, ou antes, sua necessidade. Talvez Eva precisasse de alguém de quem ela pudesse depender. Na velhice, à necessidade de se depender de alguém pode se sobrepor ou conjugar uma tendência ao isolamento, na medida em que o indivíduo negue seu desejo de pertencimento pelo medo de, simplesmente, não ter mais a quem pertencer. Segundo Both (2000), os meios sociais não acolhem o idoso numa atmosfera que contenha psicologicamente suas intensidades emocionais, significando isto fazerse da velhice um tempo de crise em que o social reforça a imagem de fragilidade e a inevitabilidade das rupturas.

Waldemar pode descobrir um campo de trabalho inesperado em outro local e ir-se do Retiro sem olhar para trás, pois enquanto está ali, o preço de ocultar a frustração de não ter alguém ou um lugar que lhe agrade e lhe satisfaça um pouco mais exige o cultivo de uma completa indiferença à instituição e aos colegas de quem ele priva a companhia no fim da vida, com exceção de quando levanta-se para lutar pelos seus direitos e dar, com isso, um sentido e uma energia novos ao quotidiano institucional, talvez excessivamente pacato para ele.

Porém, a necessidade de ver as circunstâncias e posicionar-se não o dota, nem aos colegas, da capacidade de transformar seu local de moradia em um espaço de vida suficientemente bom. Não lhes possibilita construir uma rede de relações fecunda que torne possível até a realização de um sonho por todos acalentado, mais ou menos secretamente, de poder voltar a atuar, tocar, representar, escrever e ver os seus trabalhos escritos levados à cena, trabalhar enfim. $\mathrm{O}$ tempo lhes faz pesar, a motivação é ilusória, a recordação é penosa e o isolamento é mais fácil.

Observando o estilo das relações de Hélio na instituição, percebe-se que suas idealizações a respeito da sua situação atual de vida se sustentam em vontade própria, que se apóia num otimismo cuidadosamente construído. Suas reflexões sobre o local são naturais dele, mas 
são deliberadamente criadas, cultivadas e preservadas das dificuldades exteriores, a partir das possibilidades que a realidade institucional the oferece. Por esse cultivo voluntário, que parece lutar contra as forças da desmotivação e da solidão numa interpretação forçosamente favorável da realidade, com a devida ressalva de que o movimento o conduz a uma abertura às relações, pode-se ver um subjacente sentimento de isolamento como pivô da reação deliberada. Esta realidade aparece mais manifesta, reconhecida e avaliada por outras formas nos testemunhos de seus colegas, como se vê nas palavras de Eva:

Eva: "Não se tinha, assim, muita afinidade, assim, com todo mundo, não..."

Ao se referir ao tempo de sua geração nas artes cênicas, quando ela não nutria afinidades com todos, mas apenas com os que estavam na linha de sua posição dentro daquele universo, como outros atores e diretores, define a qualidade de relação que ela mantém com os outros moradores do retiro hoje em dia. Muitos deles são antigos funcionários que trabalhavam nos bastidores, como técnicos de som, etc., que não tinham o mesmo status dos que dirigiam os espetáculos ou dos que iam à cena para atuarem como intérpretes. $\mathrm{O}$ argumento contra a atual permanência dessas pessoas no retiro é de que, na realidade, eles não eram artistas, mas simples trabalhadores que não faziam parte daquela classe de trabalho dos que atuavam. Eva mantém essa reserva rígida até hoje, tal como naquela época, em relação a esses moradores, de modo que conserva perante si mesma e perante a instituição a aura de alguém diferente, mais prestigiada.

Estas e outras condutas cumprem a função de manter vivo, de alguma forma, aquele mundo em que todos se reconhecem e que precisa ser preservado para que todos continuem se reconhecendo, ainda que alguns em uma posição desvantajosa em relação a outros. Eva é uma das responsáveis pela manutenção dessa referência, mas o que destitui um pouco o brilho de seu prestígio é a realidade geral de ofuscamento de qualquer brilho em uma residência de pessoas idosas, cansadas e, umas mais, outras menos, desiludidas, e, sobretudo, em situação (fantasiada?) de abandono.

A proposta institucional de um retiro no qual se fomente um 
balanço de vida, um local de reflexão e reorganização, termina redundando num espaço com significado de transição indiferente, tanto para quem está ali há uma semana quanto para quem reside há vinte anos. Sem uma equipe residindo no local para lhe dar infra-estrutura, de um modo ou de outro voltados cada um para si mesmo por motivos pessoais, as paredes da casa são o que realmente partilham por inteiro, mas as existências se dão em separado, como se ainda fosse imperativo um grande espaço entre seres que ocupam uma grande área em redor de si. A realidade das carências materiais e afetivas se ressente da falta de integração entre a rede de moradores, para a qual o fato de identificarem-se, em função de um tempo antigo que os associa entre si, antes contribui para afastá-los, para mantê-los como que em um lapso de espera, vivendo apenas um entreato em suas vidas, com um passado e um futuro a deter-lhes na cena.

\section{Considerações Finais}

No discurso dos entrevistados, fica evidente o sentimento de que o mundo de trabalho, de fato, os exclui, julgando-os obsoletos, sem meios de ocupar espaço em sua antiga área, ao menos do modo como o puderam fazer no passado. O uso da ilusão, como descreve Seminerio (1999), atenua a dureza da realidade da finitude, que se torna mais iminente na velhice. Para os entrevistados, esse uso auxilia no enfrentamento da redução lenta e gradativa, mas sem retorno, dos vínculos com o mundo exterior à instituição e, por conseguinte, no reconhecimento integral da finitude, representada e já parcialmente experimentada neste fim de uma era de vida profissional.

Numa situação de grande dificuldade de se efetivarem projetos psicossociais e culturais suficientemente renovadores, a proposta institucional de servir-lhes como abrigo, enquanto pertencentes a uma mesma categoria profissional, esbarra em algumas dificuldades de relacionamento importantes, com marcada influência sobre sua experiência de viver em comunidade na instituição.

Os respectivos processos de vida demonstram o esgarçamento do ritmo geral de atividades, acompanhado de um processo de fechamento sobre o si mesmo, no qual o jogo confuso entre a ilusão e a realidade, juntamente com o cultivo das reminiscências e a ocultação 
dos afetos e emoções, têm um papel decisivo na saúde dos idosos, produzindo espaços internos cada vez mais amplos em relação à atenção que dão aos seus respectivos espaços ocupados na rede institucional. Conforme o tempo de vida na instituição, o que se poderia chamar de "ensimesmamento" vai se aprofundando, sobrepondo-se a rompantes de participação no coletivo. $\mathrm{O}$ isolamento da casa do restante da comunidade, considerando o fato do universo comum de reminiscências, termina por ser especialmente restritivo. Assim, as iniciativas criadas pela direção para ventilação da vida diária não obtêm uma revitalização de referências e vivências suficiente ou durável, de vez que todos aludem a semelhantes contrastes entre a memória guardada e uma atualidade de difíceis experiências de pertencimento ao grupo formado e ao local onde vivem.

O processo de acolhida na casa é subseqüente a uma exigência simples, de que o candidato efetivamente pertença à classe profissional a que ela se destina. Porém, uma vez efetuada a mudança para o local, a adaptação ao espaço de vida dentro da rede vincular que se constrói ressalta pontos de conflito ligados à questão da aceitação mútua entre os moradores. Deste modo, aqueles que estão em situação de menor reconhecimento tendem a encontrar grandes dificuldades no convívio, com acentuado prejuízo em sua qualidade de vida emocional e relacional.

Os moradores estão no local somente pelo período de vida em que forem idosos autônomos e independentes, devido à ausência de infra-estrutura institucional para abrigar pessoas com idade avançada já com significativo grau de perda de funções. A proposta da instituição não prevê, ou ao menos não se compromete a nível estatutário, com a manutenção dos residentes quando sua situação de saúde exija cuidados que não possam ser por ela custeados financeiramente. $\mathrm{O}$ significado simbólico dessa condição de permanência lhes desautoriza, num sentido geral, a manifestação de fragilidades pessoais. Produz-se, assim, um desengajamento fundamental em relação à instituição e uma retirada dos investimentos vinculares, operados, em condições favoráveis, fora do si mesmo, na direção que Bianchi (1993 apud BOTH, 2000) ${ }^{4}$ nomeia como sentido humano do envelhecimento. Em vista disso, há

4 BIANCHI, Henri. O Eu e o Tempo. São Paulo: Casa do Psicólogo, 1993. Apud BOTH, Agostinho. Identidade Existencial na Velhice: mediações do Estado e da universidade. Passo Fundo: UPF, 2000. P. 33-34. 
um reforço dos conflitos interpessoais alternados pela indiferença afetiva recíproca, já sobremaneira impostos e sustentados pela persistência de antigas hierarquias e distanciamentos que influem sobre o teor dos vínculos.

No contexto de afastamento do trabalho, a marca da vivência na profissão perpassa do início ao fim a vida da instituição. Contudo, aquilo que os agrega por identificá-los, a saber, uma experiência de trabalho semelhante, é justamente o que compartimentaliza a instituição em espaços individuais tendentes ao fechamento e ao conflito com o outro, e, diante disso, a proposta de um local de reflexão se cumpre sem que se criem alternativas de vida mais satisfatórias dentro da instituição que as quer proporcionar.

Naturalmente submetida a circunstâncias materiais, a proposta de um modelo de espaço de plena autonomia, na falta de uma mínima equipe especializada com presença diária para gerir as necessidades básicas do quotidiano segundo as diretrizes lançadas por órgãos voltados para o trato do idoso (SOCIEDADE..., 2004) mantendo-se apenas o imóvel, a luz, a água e os moradores, a instituição não pode considerar suficientemente o fator humano ligado às condições de envelhecimento enfrentadas em um contexto de frustração, solidão e nostalgia. Este fator é o que intensifica a dificuldade de cada morador organizar seus interesses pessoais com os do ambiente e portar em si desejos inconfessos cada vez mais distantes da realidade que o outro estampa em efeito especular. Assim, termina-se por não chegar a que os indivíduos assimilem inteiramente suas vicissitudes com a suficiente continência psíquica para organizarem-se num ambiente favorável à solução das tensões a que todos estão sujeitos, num espaço que, a um só tempo, é de carência e partilha.

\title{
FRAGMENTS OF A HETEROGENEOUS SPEECH OF AGED IN A HOMOGENEOUS SPACE OF LACK AND SHARE
}

\begin{abstract}
This work searchs describe-interpret the current speech among the inhabitants of an Institution of Long Permanence organized for a public composed for aged artists without resources of proper housing.
\end{abstract}


One searchs through this analysis to establish parameters to contribute with the reflection on institutional models directed toward this age band guided for social groups strict delimited by criteria as ethnic-cultural profession, origins, spirituality or others.

Keywords: Elderly. Artists. Institution.

\section{REFERÊNCIAS}

BEAUVOIR, Simone de. A Velhice. Rio de Janeiro: Nova Fronteira, 1990.

BORN, Tomiko; BOECHAT, Norberto Seródio. A Qualidade dos Cuidados ao Idoso Institucionalizado. In: FREITAS, Elisabete Viana de et al. (Org.). Tratado de Geriatria e Gerontologia. Rio de Janeiro: Guanabara Koogan, 2002. P. 768-777.

BOTH, Agostinho. Identidade Existencial na Velhice: mediações do Estado e da universidade. Passo Fundo: UPF, 2000.

BRASIL. Lei ${ }^{\circ} 10.741$, de $1^{\circ}$ de outubro de 2003. Decreta e sanciona o Estatuto do Idoso. Diário Oficial [da] República Federativa do Brasil, Poder Executivo, Brasília, DF, 3 out. 2003. Disponível em: < http://www.planalto. gov.br/ccivil_03/Leis/2003/L10.741.htm>. Acesso em: 20 agosto 2007.

BULLA, Leonia Capavarde; MEDIONDO, Marisa Silvana Zazzetta de. Velhice, Dependência e Vida Cotidiana Institucional. In: CORTELLETTI, Ivonne Assunta; CASARA, Míriam Bonho; HERÉDIA, Vania Beatriz Merlotti. (Org.). Idoso Asilado: um estudo gerontológico. Caxias do Sul: Edipucrs, 2004. P. 87-107.

MAINGUENEAU, Dominique. Análise de Textos de Comunicação. São Paulo: Cortez, 2001.

OSTROWER, Faiga. Criatividade e Processos de Criação. Petrópolis: Vozes, 1977. 
POSSENTI, Sírio. O que significa “ O Sentido Depende da Enunciação?” In: BRAIT, Beth (Org.). Estudos Enunciativos no Brasil: histórias e perspectivas. Campinas: Pontes/Fapesp, 2001. P. 187-199.

QUADROS, Marcelo Pereira de. As Implicações Psicológicas do Idoso Institucionalizado. 1998. 165 f. Trabalho de Conclusão de Curso (Graduação em Psicologia), Universidade Luterana do Brasil, Canoas, 1998.

SEMINERIO, Franco Lo Presti. Existência e Finitude. In: PY, Lygia (Org.). Finitude: uma proposta para reflexão e prática em gerontologia. Rio de Janeiro: NAU, 1999. P. 21-30.

SOCIEDADE Brasileira de Geriatria e Gerontologia. Seção São Paulo. Instituição de Longa Permanência para Idosos: manual de funcionamento. São Paulo: SBGG, 2004.

Recebido em: 24.01.2007

$1^{a}$ reformulação: 08.03.2007

$2^{a}$ reformulação: 10.08.2007

Aceite final: 30.08.2007 